Article

\title{
Potential of Offshore Wind Energy and Extreme Wind Speed Forecasting on the West Coast of Taiwan
}

\section{Pei-Chi Chang ${ }^{1,2, *}$, Ray-Yeng Yang ${ }^{1,2}$ and Chi-Ming Lai ${ }^{2,3}$}

1 Tainan Hydraulics Laboratory, National Cheng Kung University, 1 University Road, Tainan 701, Taiwan; E-Mail: ryyang@ mail.ncku.edu.tw

2 Research Center for Energy Technology and Strategy, National Cheng Kung University, 1 University Road, Tainan 701, Taiwan

3 Department of Civil Engineering, National Cheng Kung University, 1 University Road, Tainan 701, Taiwan; E-Mail: cmlai@mail.ncku.edu.tw

* Author to whom correspondence should be addressed; E-Mail: pamchang@ mail.ncku.edu.tw; Tel.: +886-6-2371938 (ext. 711); Fax: +886-6-3840886.

Academic Editor: Frede Blaabjerg

Received: 21 November 2014 / Accepted: 11 February 2015 / Published: 27 February 2015

\begin{abstract}
It is of great importance and urgency for Taiwan to develop offshore wind power. However, relevant data on offshore wind energy resources are limited. This study imported wind speeds measured by a tidal station and a buoy into the software WAsP to estimate the high-altitude wind speeds in the two areas. A light detection and ranging (Lidar) system was set up near the tidal station and buoy. High-altitude wind speeds measured by the Lidar system were compared with the WAsP-estimated values, and it was discovered that the two data sets were consistent. Then, long-term wind speed data observed by buoys and tidal stations at various locations were imported into WAsP to forecast wind speeds at heights of 55-200 m on the west coast of Taiwan. The software WAsP Engineering was used to analyze the extreme wind speeds in the same areas. The results show that wind speeds at $100 \mathrm{~m}$ are approximately $9.32-11.24 \mathrm{~m} / \mathrm{s}$, which means that the coastal areas of west Taiwan are rich in wind energy resources. When a long-term 10 -min average wind speed is used, the extreme wind speed on the west coast is estimated to be between 36.4 and $55.3 \mathrm{~m} / \mathrm{s}$.
\end{abstract}

Keywords: wind; wind energy; wind speed; extreme wind speed; offshore wind 


\section{Introduction}

\subsection{Wind Energy Estimation}

The Taiwan government expects that by 2025, renewable energy will constitute $15.1 \%$ of the country's total power generation capacity. Wind energy alone will constitute $5.3 \%$, which shows that wind power is the fastest growing and accounts for largest proportion of all renewable energy resources. However, in Taiwan, terrestrial wind energy is restricted and has almost been completely developed; however, offshore wind energy resources are rich and undeveloped, which underlines the importance of developing an offshore wind energy system.

According to the International Electrotechnical Commission (IEC) standard [1], before establishing an offshore wind farm, at least one year of marine meteorological observation data is required to accurately understand the site's wind energy potential. These data are used to estimate the wind farm's setup cost and power generating capacity, etc. Wind energy evaluation is the primary factor in the development of an offshore wind farm; long-term wind speed observations at an adequate height are the basis for evaluation. In recent years, offshore wind turbines have become very large. Currently in the market, a majority of the offshore wind turbine installations have a capacity of $3 \mathrm{MW}$, and offshore wind turbines are approximately $100 \mathrm{~m}$ high. In Taiwan, wind speed data come primarily from meteorological stations of the Central Weather Bureau, whose near-shore terrestrial stations are all below $10 \mathrm{~m}$; as a result, so far there has been no offshore wind speed observation.

The software WAsP has robust and reliable tools for wind climate characterization and wind energy potential assessment [2]. Lima and Filho [2] conducted a wind resource evaluation and wind energy assessment for São João do Cariri in Paraiba state of northeast Brazil for the period from 2006 to 2009. Onat and Ersoz [3] used WAsP to determine the characteristics of wind climate and energy potential and produced detailed analyses for three regions of Turkey. Palaiologou et al. [4] used GIS and WAsP as basic calculation platforms to test and evaluate measurements from 15 wind turbine sites by creating six alternative scenarios in the island of Lesvos, Greece. Djamai and Merzouk [5] used WAsP to investigate the possibility of setting up a $10 \mathrm{MW}$ wind farm in Adrar, a region located in the south of the country.

Accurate measurement of the wind speed profile in an atmospheric boundary layer is difficult. Studies have used Light Detection and Ranging (Lidar) to reveal wind speed profiles at high altitudes. Sanz Rodrigo et al. [6] illustrated an inter-comparison experiment involving one Sonic Detection and Ranging (Sodar) unit and two Lidars (pulsed and continuous-wave). The wind profilers are benchmarked with respect to a reference cup anemometer and other mast-based instruments, and a procedure for testing and evaluating remote sensing instruments that makes use of two test sites in flat and complex terrains is presented. Wood et al. [7] observed the airflow above the River Thames in central London using a scanning Doppler Lidar, a scintillometer and sonic anemometers. Coutu et al. [8] proposed the use of combined 3-D GIS and Lidar data to retrieve all the information necessary to apply the Norm on a large set of buildings. Some studies have used Lidar to measure offshore marine wind speed profiles. For instance, Standridge et al. [9] demonstrated the utility of the new approach. Measurements made by a laser wind sensor mounted on a floating buoy were first compared with measurements from a second laser wind sensor mounted on a nearby small island, 
for which the variation co-efficient is high (>99\%). Pichugina et al. [10] illustrated a motion-compensated, high-resolution Doppler Lidar-based wind measurement system that is capable of providing required information on offshore winds at several heights. It uses specialized scanning and analysis techniques to obtain wind profiles at a distance from the platform where the flow is not subject to platform-induced distortion effects.

\subsection{Extreme Wind Speed Forecast}

Both a wind-resistant design and a structural safety assessment require reliable extreme wind speed measurements. The extreme speeds may cover a 50-year or even a 100 -year return period. When a certain amount of extreme data is obtained, a statistical cumulative distribution function can be used to describe the distribution status of the extreme values [11]. We often use extreme wind speed to evaluate offshore wind energy sites and to determine the required structural strength of a wind turbine design. Estimation methods for extreme wind speed are divided into two major categories [12]: annual-maxima and Peaks-Over-Threshold (POT). In an annual-maxima method, standard Gumbel (SG) uses a Gumbel distribution function to estimate the distribution pattern of maxima at several defined periods in a year. Harris [13] used parametric plotting positions and a weighted least-squares method for the Gumbel distribution, which is called a modified Gumbel (MG). The POT method gathers wind speed data that exceed a threshold for analysis, and this method should gather enough data to reduce the uncertainty of the outcome.

The software used in this study to estimate extreme wind speed is WAsP Engineering 3.0. It uses a Gumbel distribution with a probability-weighted moment method. This distribution function is generated from a double exponential function:

$$
\begin{gathered}
F(v)=\exp \left(-\exp ^{-Y}\right) \\
Y=a(v+b)(-\infty<v<\infty) \\
F(v)=\exp \left(-\exp ^{-Y}\right)=\exp \left(-\exp ^{-a(v+b)}\right)
\end{gathered}
$$

In the formula, $Y$ is called a canonical variable; $F(v)$ is called a cumulative distribution function of extreme value $v$; and $a, b, k$, and $u$ are characteristic coefficients for each distribution function. The Gumbel distribution function's characteristic coefficients, $a$ and $b$, are given by the following expressions:

$$
\begin{gathered}
a=\frac{1}{0.78 \sigma} \\
b=\mu-0.45 \sigma
\end{gathered}
$$

In these formulae, $\mu$ is the average and $\sigma$ is the mean square root.

We can use these formulae to estimate possible extreme values $v(T)$ for wind speed for a T-year return period:

$$
\begin{gathered}
F(v)=\exp \left(-\exp ^{-Y}\right)=\exp \left(-\exp ^{-a(v+b)}\right)=1-\left(\frac{1}{T}\right) \\
v(T)=-\frac{1}{a} \ln \left[\ln \left(\frac{T}{T-1}\right)\right]+b
\end{gathered}
$$


Lee et al. [14] used the maxima of daily and monthly 3-second and 600-second average wind speeds as inputs to estimate extreme wind speed. They discovered that extreme wind speed estimates based on 3 -second average wind speed were higher than estimates based on 600-second average wind speed. Monthly maxima were found to be reliable for extreme wind speed estimation. An and Pandey [12] discovered that the SG method tends to provide an upper limit of wind speed for a 50/500 year design. The MIS method, compared to the POT method, is less susceptible to threshold fluctuation, and it has lower sensitivity.

There is a pressing need to develop an offshore wind farm right away in Taiwan. However, construction of a marine meteorological mast to obtain long-term offshore meteorological data cannot be completed in a short period, and the use of Lidar for wind energy analysis has only recently begun. Therefore, this study used long-term meteorological data measured by tidal stations and buoys and the WAsP program to establish a wind speed forecast at heights between 50 and $200 \mathrm{~m}$ for the west coast of Taiwan. The software WAsP Engineering 3.0 (Ris $\varnothing$ Campus, Denmark, 2012) was used to analyze extreme wind speed in the same area.

\section{Research Methods}

\subsection{Light Detection and Ranging (Lidar)}

The Lidar system used in this study is designed to remotely measure wind speed and wind direction. This equipment has a motion compensation function; thus, it can be used in a floating carrier. The Lidar system can measure wind speed, direction and turbulence strength once per second for six altitude profiles ranging from 30 to $200 \mathrm{~m}$ in the carrier. This study defines measurement altitudes of $55 \mathrm{~m}, 70 \mathrm{~m}, 90 \mathrm{~m}, 110 \mathrm{~m}, 150 \mathrm{~m}$ and $200 \mathrm{~m}$ above the Lidar height, and data for each altitude are the average of a range of $\pm 20 \mathrm{~m}$. Lidar's primary parameters and dimensions are briefly introduced in Table 1 and Figure 1.

Table 1. Specifications of the Lidar system used.

\begin{tabular}{lc}
\hline Specification item & Range \\
\hline Operating wavelength & $1550 \mathrm{~nm}$ \\
Wind speed range & $0-90 \mathrm{~m} / \mathrm{s}$ \\
Sensing range & 30 to $150 \mathrm{~m}$ \\
Number of range gates & $3-6$ \\
Range gate depth & $\pm 20 \mathrm{~m}$ \\
Wind speed accuracy & $\pm 0.5 \mathrm{~m} / \mathrm{s}$ \\
Wind direction accuracy & $\pm 1^{\circ}$ \\
Relative angular accuracy & $\pm 2^{\circ}$ \\
Data output rate & $1 \mathrm{~Hz}$ \\
\hline
\end{tabular}

\subsection{WAsP}

Wind Atlas Analysis and Application Program (WAsP), a wind energy estimation tool developed by the Wind Energy Department at the Risø National Laboratory (DTU Wind Energy) in 1987, is a sophisticated yet easy-to-use wind energy analysis tool that provides wind data analysis, wind climate 
estimation, and sittings of wind turbines [15]. This study first compares WAsP assessment results with Lidar field measured data to verify the software's accuracy for high altitude wind speed forecasts. Then, long-term low and high altitude wind power observation data from around Taiwan are imported into the software to assess high altitude wind power resources on the west coast of Taiwan.

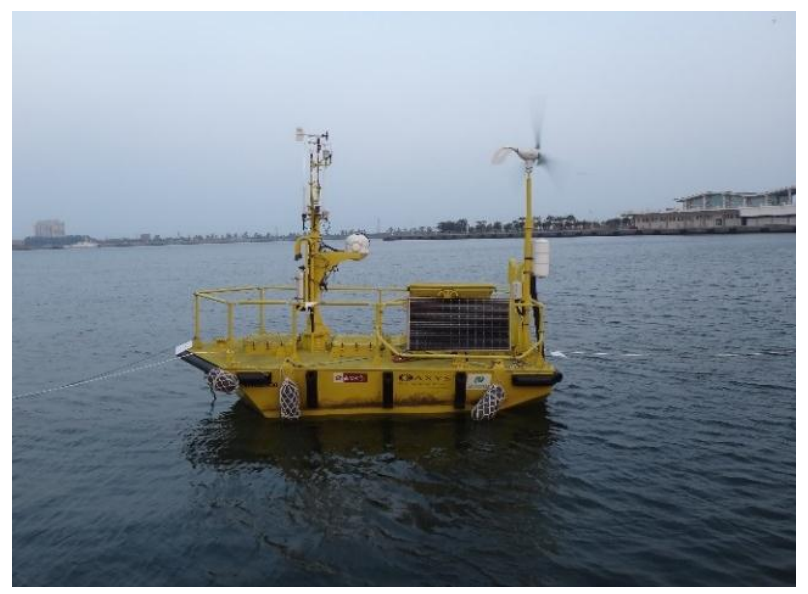

Figure 1. Lidar used in this study.

\subsection{Empirical Simulation Data versus Lidar Detection Results}

This study first imports the marine tidal station (in Miaoli) and marine buoy (in Tainan) measurements of low-altitude wind speeds (average 10-min values) into WAsP to estimate the high-altitude wind speeds at the two sites. Then, a Lidar system is set up near the tidal station and buoy, and high altitude wind speed data are measured by Lidar and used to verify the WAsP-simulated high altitude wind speed. All the measurements by the tidal station, buoy and the Lidar system were conducted during the same time period.

\subsubsection{Miaoli Region}

There is a Central Weather Bureau Waipu tidal station for long-term measurement in Miaoli, which is approximately $10 \mathrm{~km}$ from the Lidar system location. The relative locations of the two sites are shown in Figure 2. This study used field measured terrain data and actual land use to establish a 5-m contour map and a surface roughness diagram, as shown in Figure 3a,b, respectively. Then, we used the Observed Wind Climate (OWC) Wizard program with the contour map and surface roughness diagram in WAsP to process wind data from the tidal station and obtained wind speed data for the Lidar location. Both the data period of the tidal station and the measurement time of the Lidar are from 17 December 2013 to 17 February 2014.

\subsubsection{Tainan Region}

There is a Qigu buoy for long-term measurement by the Central Weather Bureau in Tainan, which is $10 \mathrm{~km}$ from the Lidar system. The locations of the two sites are shown in Figure 4. This study also uses a 5-m contour map and a surface roughness diagram (from actual land use) (shown in Figure 5) as well as the software WAsP to process the wind data from the Qigu buoy. Thus, the high-altitude 
wind speed data at the Lidar location was obtained. Both the data period of the buoy and the measurement time of the Lidar system are from 22 June to 16 October 2013.

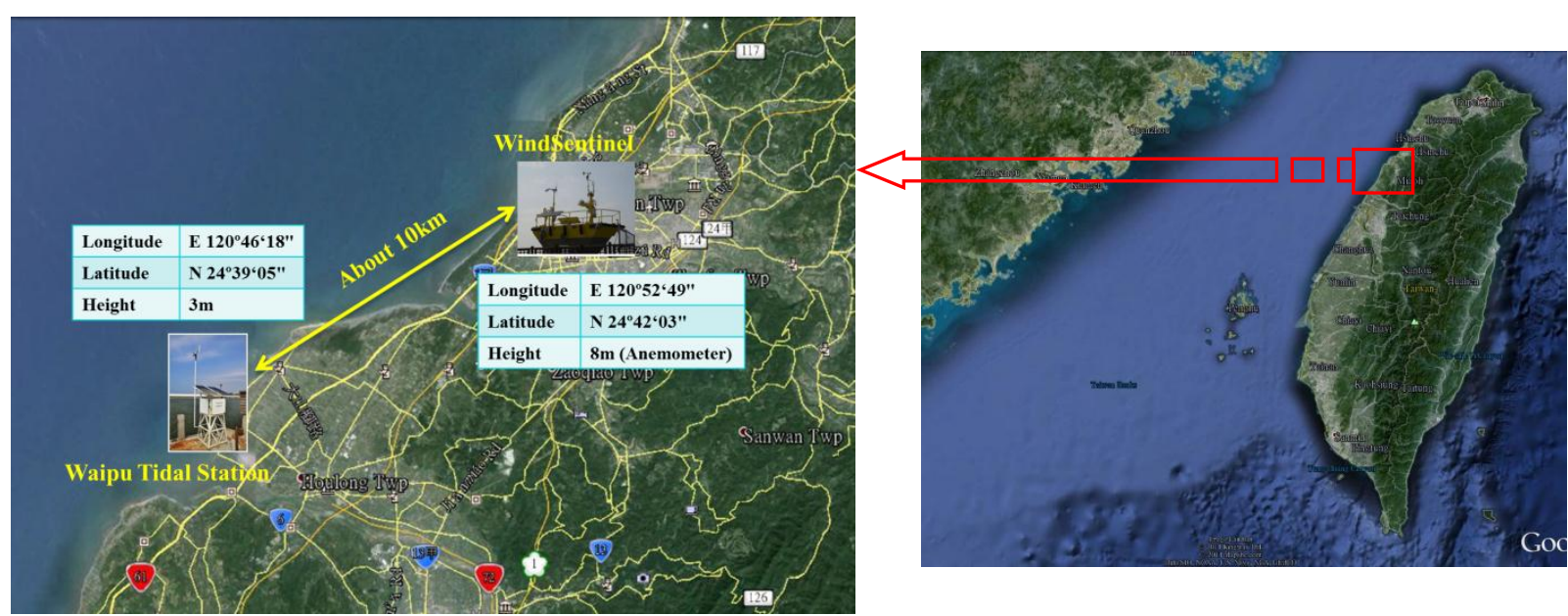

Figure 2. Locations of the Waipu tidal station and Lidar system in the Miaoli area.

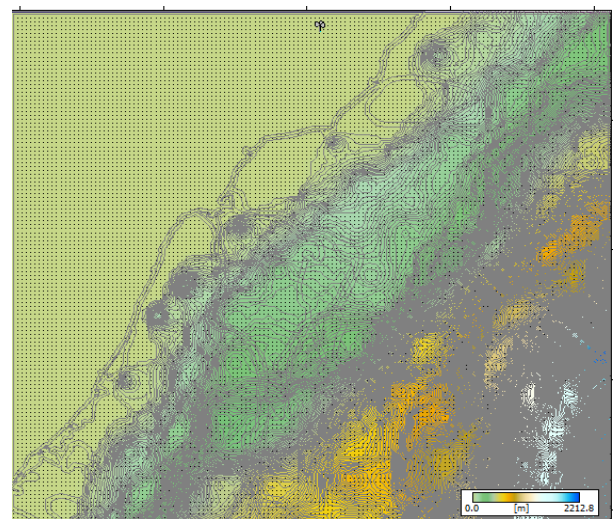

(a)

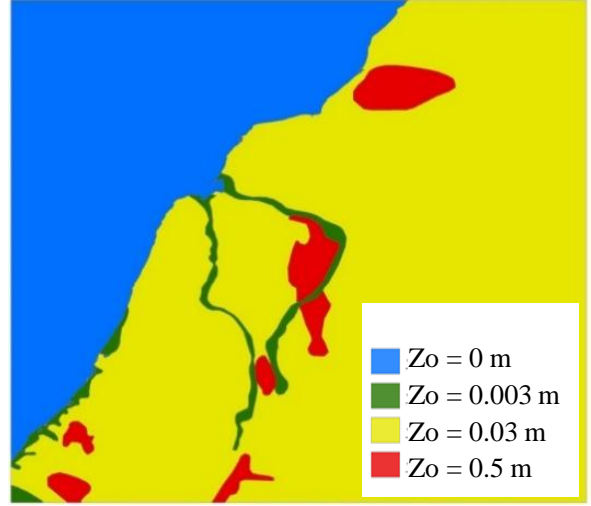

(b)

Figure 3. Contour map and surface roughness diagram in the Miaoli area. (a) 5-m contour map; (b) Surface roughness diagram.

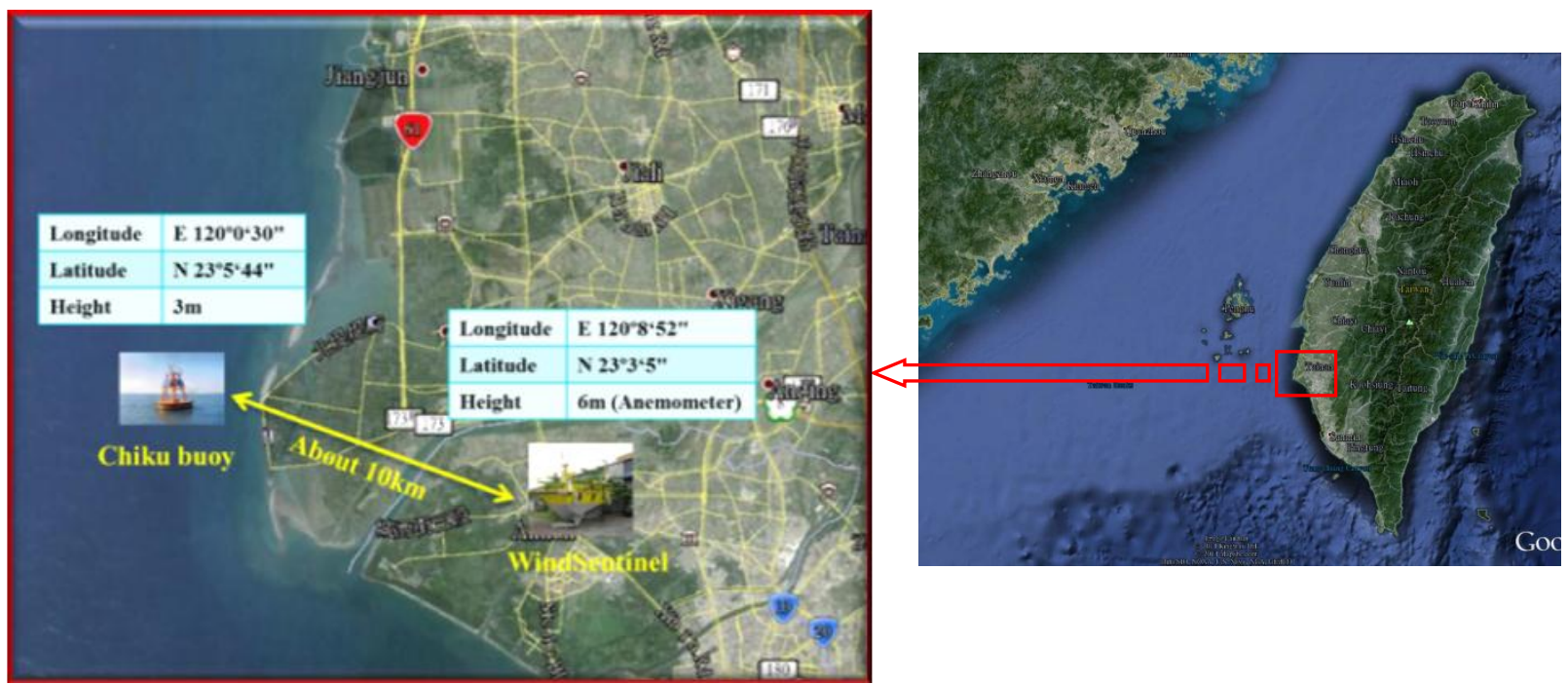

Figure 4. Locations of the Qigu buoy and Lidar system in the Tainan area. 


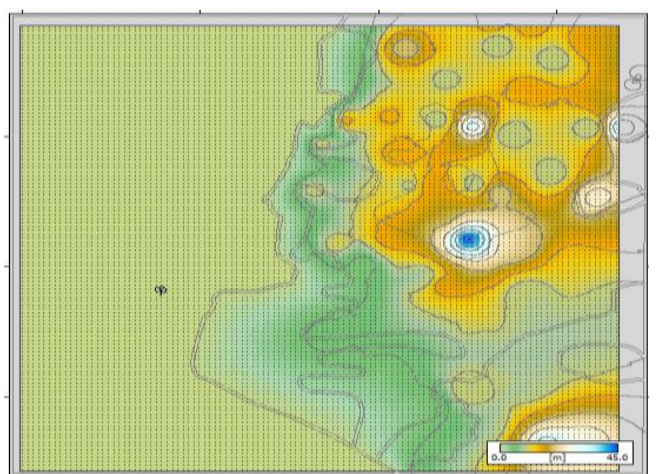

(a)

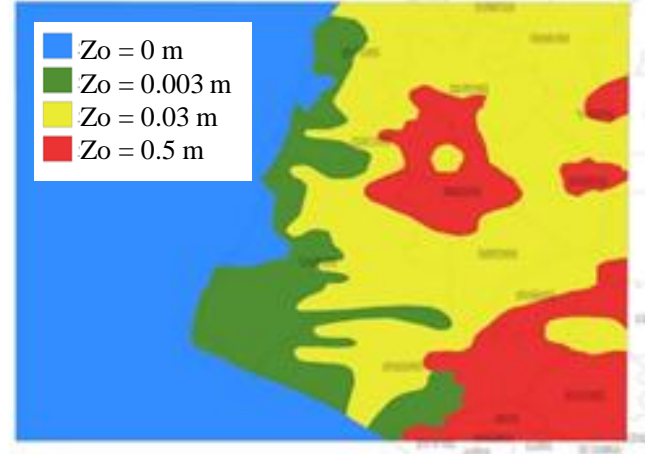

(b)

Figure 5. Contour map and surface roughness diagram in the Tainan area. (a) 5-m contour map; (b) Surface roughness diagram.

\subsection{Analysis of Wind Power Resources on the West Coast of Taiwan}

By comparing the empirical simulation data with the Lidar results, we can confirm whether data were imported to WAsP from a long-term measurement tidal station or from a near-shore buoy; the WAsP simulated results show no significant differences when compared with the Lidar field detection, as elaborated in Section 3.1. Currently, Taiwan has no offshore high-altitude wind speed data. This study collects measured average wind speed (in 10-min intervals) from long-term observations on the west coast of Taiwan, as listed in Table 2. The software WAsP is used to perform wind speed analysis for the west coast of Taiwan (Hsinchu, Miaoli, Taichung, ChangHua, Yunlin, Chiayi and Tainan, as shown in Figure 6).

Table 2. Data from long-term observations on the west coast of Taiwan.

\begin{tabular}{ccccc}
\hline Area & Station & Longitude (east) & Latitude (north) & Height (m) \\
\hline (a) Hsinchu & Hsinchu Buoy & 120.8439 & 24.7608 & 2 \\
(b) Miaoli & Waipu Tidal Station & 120.7717 & 24.6514 & 6 \\
(c) Taichung & Lukang Meteorological Station & 120.4222 & 24.0769 & 6 \\
(d) Changhua & Lukang Meteorological Station & 120.4222 & 24.0769 & 6 \\
(e) Yunlin & Mailiao Tidal Station & 120.1607 & 23.7861 & 6 \\
(f) Chiayi & Wai-san-ting-chou Meteorological Station & 120.01 & 23.26 & 10 \\
(g) Tainan & Qigu Buoy & 120.0083 & 23.0956 & 3 \\
\hline
\end{tabular}

Topography and landform (including surface roughness and obstacles) are major factors affecting wind atlas distribution. The landform can alter wind strength and direction, and high surface roughness can dampen wind speed. Therefore, in WAsP simulations, the accuracy of the landform and roughness data has a direct impact on the credibility of the simulation results.

To improve the reliability of wind energy simulation parameters, this study specifically uses landform measurement data and images, and it invests a large amount of time to draw a $5 \mathrm{~m}$ contour map. WAsP provides a roughness related specification, and it uses actual land utilization to draw the surface roughness. This study uses the map editor in WAsP to manage and create all landform and roughness image in the simulation areas. Surface roughness and $5 \mathrm{~m}$ contour maps for the simulation areas are shown in Figure 7. 

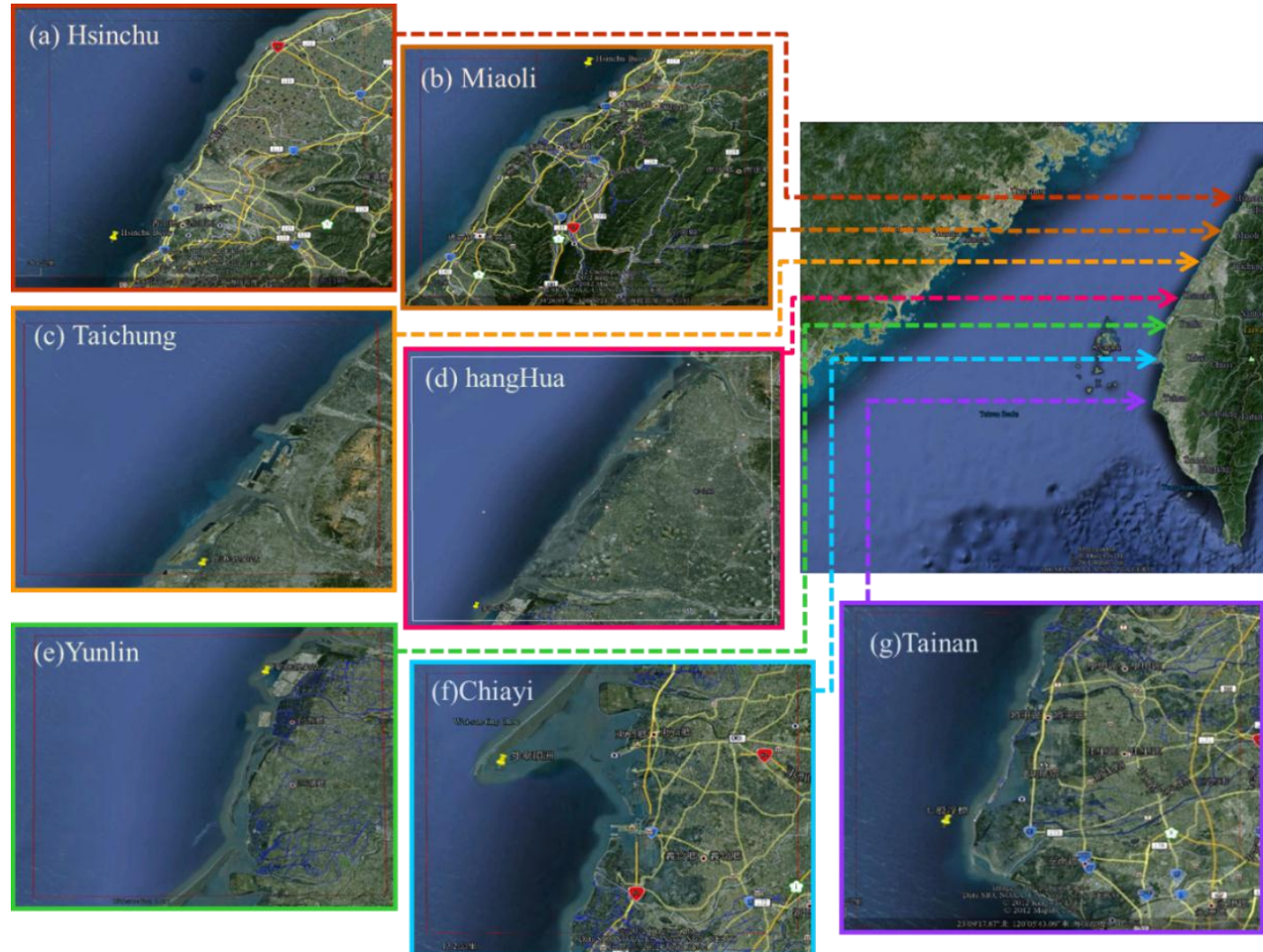

Figure 6. Developmental offshore wind farm in western Taiwan.

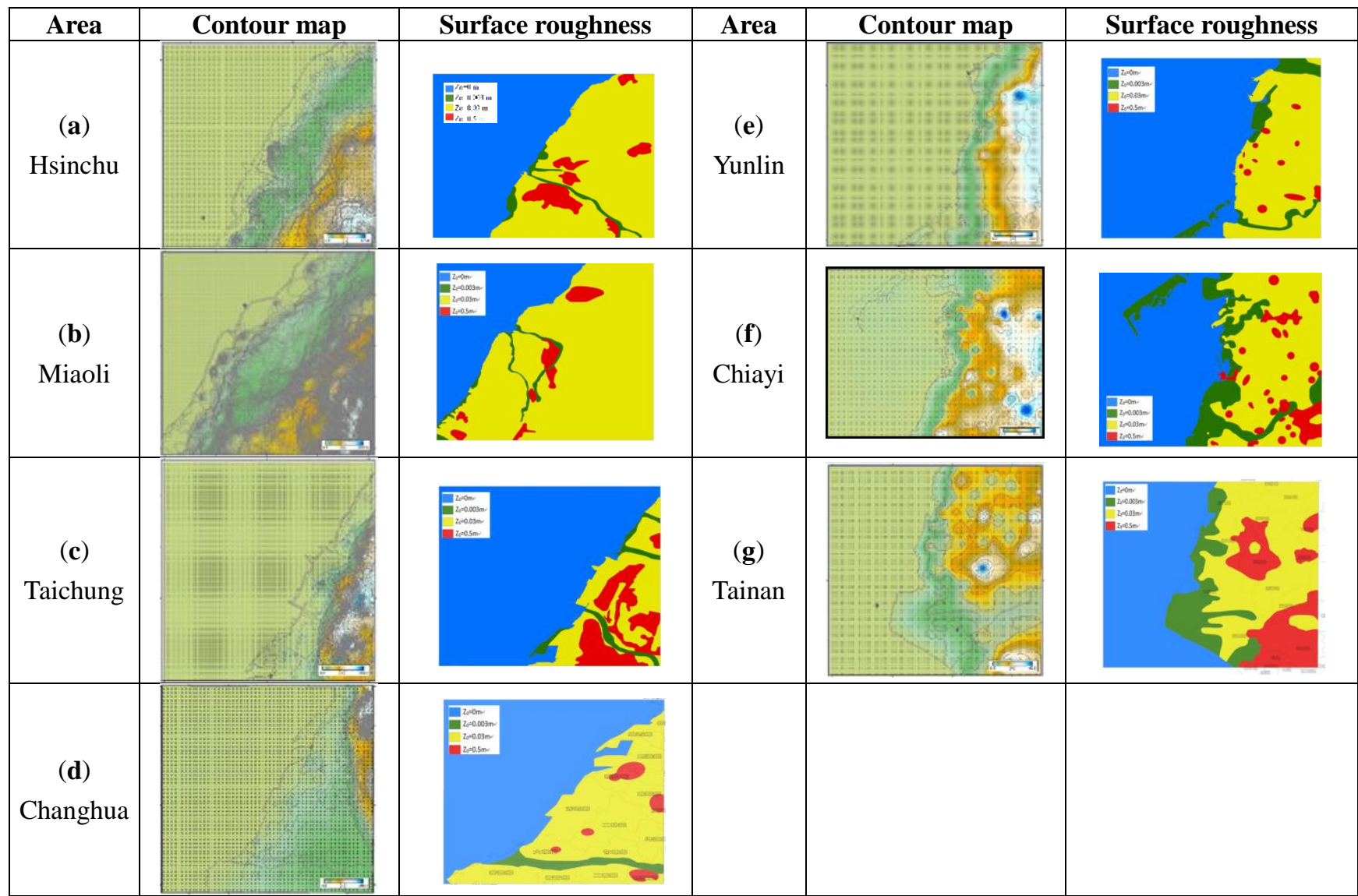

Figure 7. Contour map and surface roughness in the simulation areas. 


\subsection{Extreme Wind Speed Analysis}

To use the software WAsP Engineering 3 [15], meteorological data and landform maps should be imported into the software to obtain extreme wind speed estimations. Meteorological data sources and landform map creation are described in Section 2.4. The meteorological data from various anemometers are arranged according to the categories of short-term and long-term average wind speed in $10 \mathrm{~min}$ and gust wind speed. Considering that wind turbine's major components are $100 \mathrm{~m}$ above ground and that anemometer measurement height is relatively low, after the software accepts the arranged meteorological data, the height at which the extreme wind speed is calculated should be set to $100 \mathrm{~m}$ to ensure that the calculated extreme wind speed matches the situation at the wind turbine's principal axis. Finally, the extreme wind speed at $100 \mathrm{~m}$ is obtained for a 50 -year return period.

\section{Results and Discussion}

\subsection{Lidar Field Data versus WAsP Simulation Results}

We compared wind speeds at different heights $(55 \mathrm{~m}, 70 \mathrm{~m}, 90 \mathrm{~m}, 110 \mathrm{~m}, 150 \mathrm{~m}$ and $200 \mathrm{~m})$ measured by the Lidar system with WAsP simulated results for the same measurement period in the Miaoli and Tainan regions, as shown in Figure 8. In the figure, the horizontal axis is the measurement time, and the vertical axis represents wind speed at 6 different heights. The green line represents the Lidar-detected data; the red line represents WAsP-simulated results. The comparison shows no significant variation between the two. R-squared values from the regression analysis for Miaoli and Tainan are in the range of $0.8-0.9$ and $0.9-1$, respectively, which demonstrates that low-altitude wind speed field data can be processed by WAsP to obtain a fairly reliable forecast for high-altitude wind speeds.
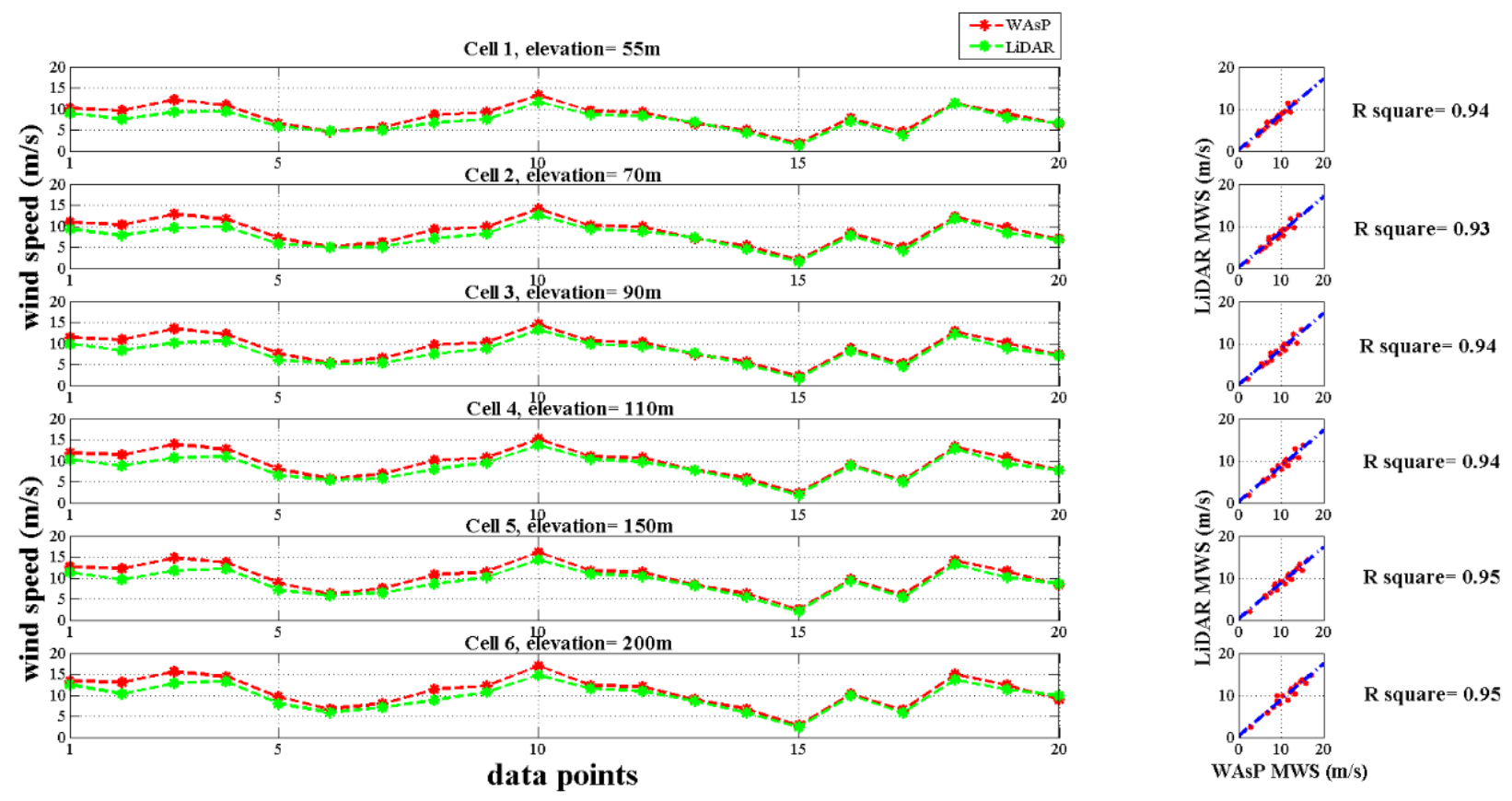

(a)

Figure 8. Cont. 

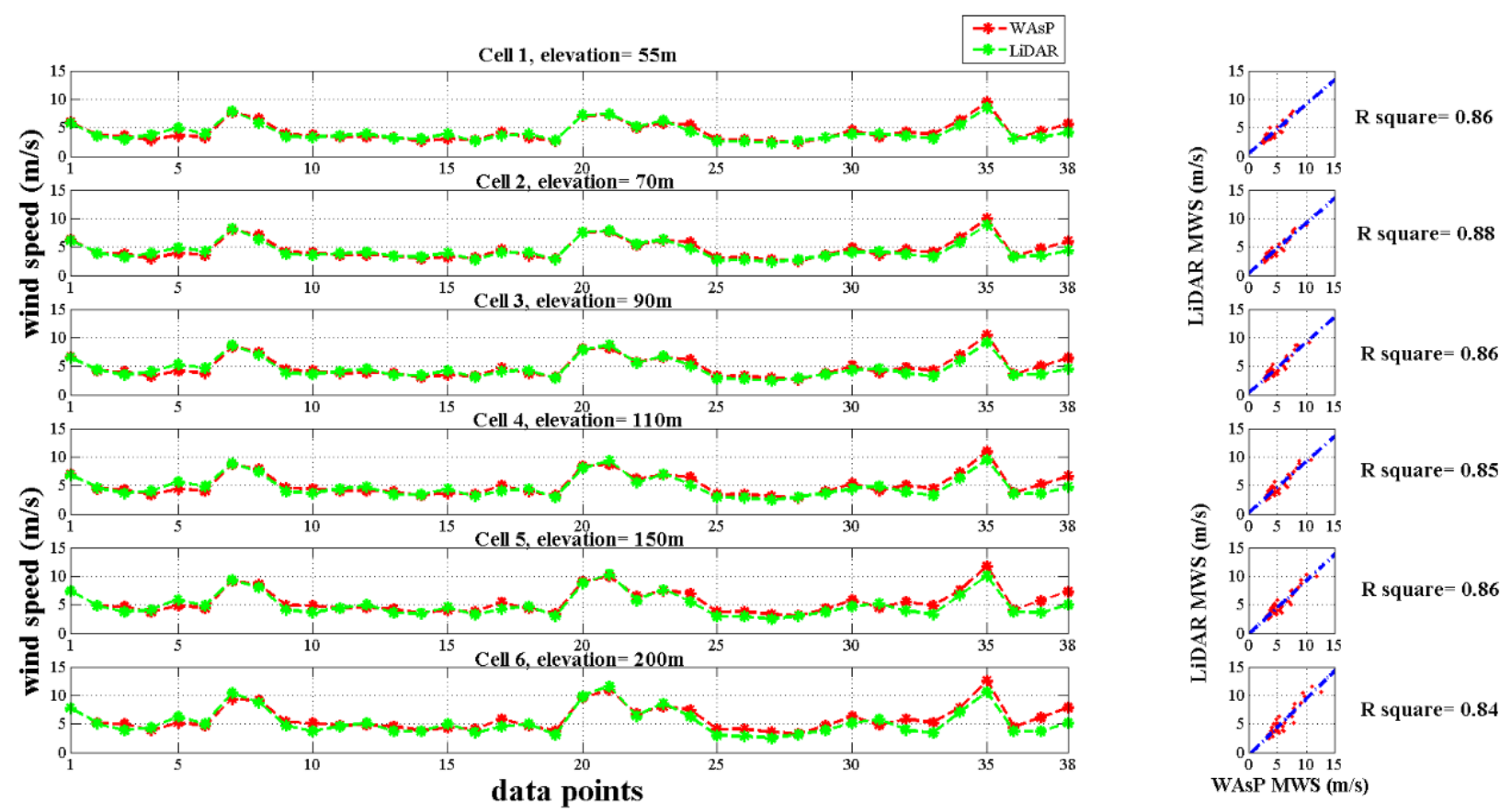

(b)

Figure 8. WAsP-simulated result versus Lidar field measured data (left: time sequence; right: regression analysis). (a) Miaoli region; (b) Tainan region.

\subsection{Wind Speed and Wind Power Density Estimations on the West Coast of Taiwan}

This study uses the software WAsP to estimate the offshore wind energy potential in west Taiwan. The simulation areas include near-shore and offshore areas in Hsinchu, Miaoli, Taichung, ChangHua, Yunlin, Chiayi and Tainan. Currently, $3 \mathrm{MW}$ offshore wind turbines make up more than 50\% of the market, and hub height is approximately $100 \mathrm{~m}$. The WAsP simulation focuses on wind speed at $100 \mathrm{~m}$; the results are shown in Figure 9. The wind direction is mainly northeast due to the influence of monsoons on the west coast of Taiwan. In terms of wind speed, the average wind speed at $100 \mathrm{~m}$ is approximately $9.32-11.24 \mathrm{~m} / \mathrm{s}$ on the west coast of Taiwan, which is close to a previous forecast [16] but is far above the $5.8 \mathrm{~m} / \mathrm{s}$ [17] in Green Island at a neighboring coastal area of Hongkong (station height is $105 \mathrm{~m}$ ). Of the neighboring coastal areas, three regions, Hsinchu, ChangHua and Yunlin, have higher speeds of approximately $10.69-11.24 \mathrm{~m} / \mathrm{s}$. Wind power density at $100 \mathrm{~m}$ in the West Taiwan coastal area is approximately $1079-2665 \mathrm{~W} / \mathrm{m}^{2}$, well beyond the previous forecast ([16,18]) $\left(700 \mathrm{~W} / \mathrm{m}^{2}\right.$ in south China, $252 \mathrm{~W} / \mathrm{m}^{2}$ [17] in Green Island, station height $105 \mathrm{~m}$ ) for the neighboring Hongkong coastal area. Of the neighboring regions, three regions, Miaoli, ChangHua and Yunlin, have higher densities of approximately $1723-2665 \mathrm{~W} / \mathrm{m}^{2}$. Estimated wind speeds and wind power densities at other heights are shown in Table 3. 


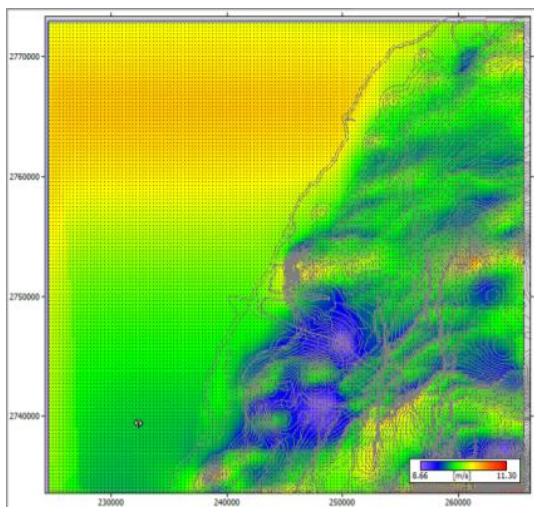

(a) Hsin Chu

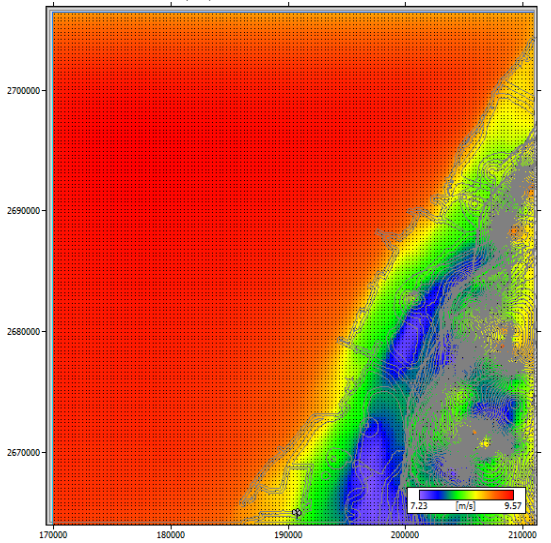

(c) Tai Chung

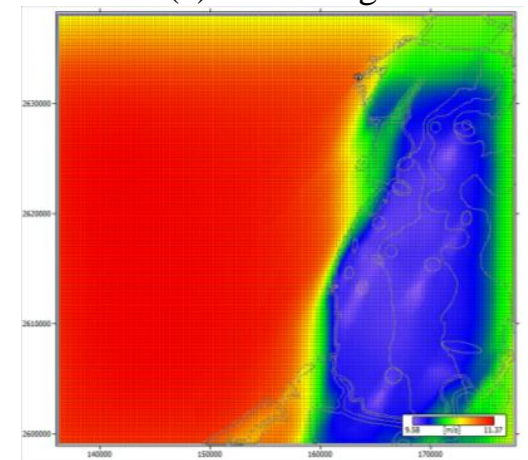

(e) Yun Lin

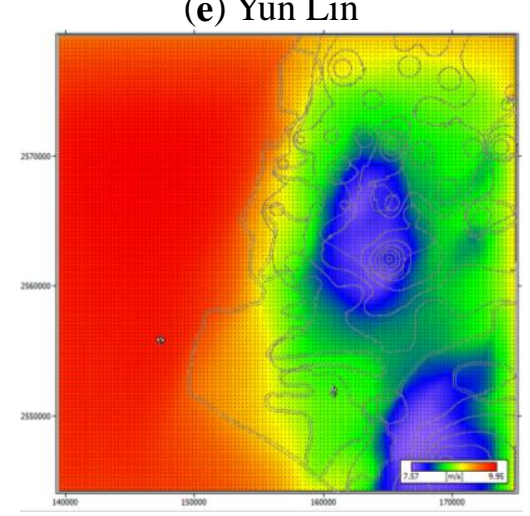

(g) Tainan

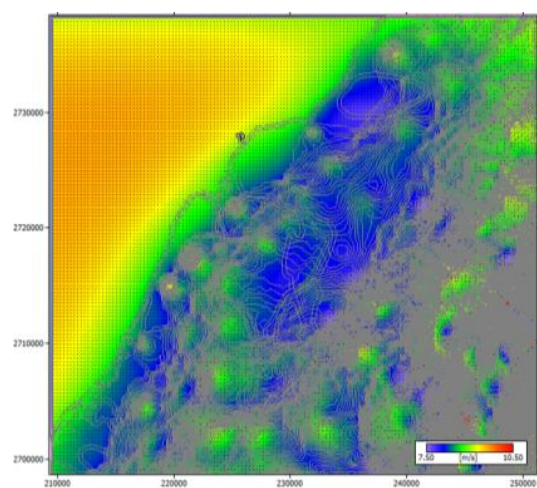

(b) Miao Li

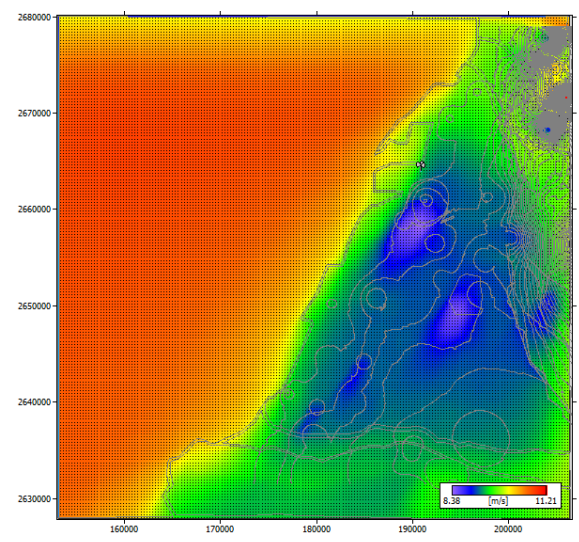

(d) Chang Hua

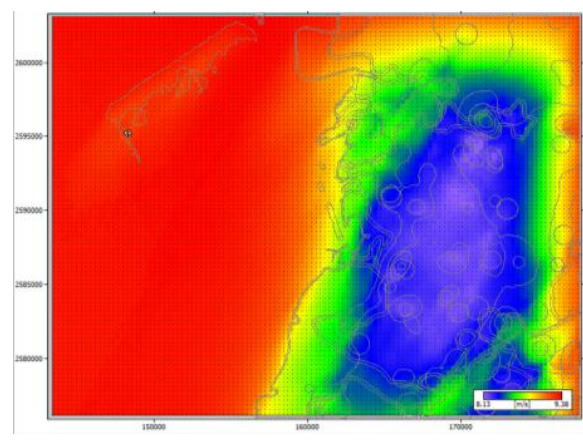

(f) Chia Yi 
Table 3. Average wind speed and wind power density.

\begin{tabular}{|c|c|c|c|c|c|c|c|c|}
\hline \multirow{2}{*}{ Area } & \multicolumn{4}{|c|}{ Wind speed (m/s) } & \multicolumn{4}{|c|}{ Wind power density $\left(\mathrm{W} / \mathrm{m}^{2}\right)$} \\
\hline & $55 \mathrm{~m}$ & $100 \mathrm{~m}$ & $150 \mathrm{~m}$ & $200 \mathrm{~m}$ & $55 \mathrm{~m}$ & $100 \mathrm{~m}$ & $150 \mathrm{~m}$ & $200 \mathrm{~m}$ \\
\hline (a) Hsin Chu & 10.32 & 11.24 & 12.06 & 12.65 & 1228 & 1563 & 1920 & 2209 \\
\hline (b) Miao Li & 8.97 & 9.54 & 10.00 & 10.34 & 2326 & 2665 & 3046 & 3344 \\
\hline (c) Tai Chung & 8.68 & 9.44 & 10.12 & 10.61 & 949 & 1187 & 1442 & 1647 \\
\hline (d) Chang Hua & 9.91 & 10.69 & 11.37 & 11.85 & 1417 & 1723 & 2032 & 2276 \\
\hline (e) Yun Lin & 10.42 & 11.24 & 11.95 & 12.46 & 1412 & 1745 & 2094 & 2371 \\
\hline (f) Chia Yi & 8.75 & 9.32 & 9.79 & 10.13 & 967 & 1170 & 1365 & 1516 \\
\hline (g) Tainan & 8.95 & 9.84 & 10.66 & 11.23 & 812 & 1079 & 1377 & 1621 \\
\hline
\end{tabular}

\subsection{Extreme Wind Speed Analysis Results for the West Coast of Taiwan}

Average wind speed in $10 \mathrm{~min}$ and maximum instantaneous gust speed from long-term and short term meteorological data are used as input data to estimate four groups of extreme wind speeds in each of seven west coastal areas in Taiwan, as shown in Table 4. When long-term 10 min average wind speed is used as the basis for calculation, the extreme wind speeds in west Taiwan coastal areas are in the range of $36.4-55.3 \mathrm{~m} / \mathrm{s}$. If the long-term $10 \mathrm{~min}$ maximum instantaneous gust is used as the calculation basis, then the extreme wind speed will rise to $57.2-82.8 \mathrm{~m} / \mathrm{s}$. If short-term $10 \mathrm{~min}$ average wind speed and maximum instantaneous gust are used as the calculation basis, then the extreme wind speeds are 36.1-43.0 and 51.5-62.6 m/s, respectively. This shows that whether short-term or long-term data are used, extreme wind speeds calculated from average wind speed are always lower than the extreme wind speeds calculated from maximum gust.

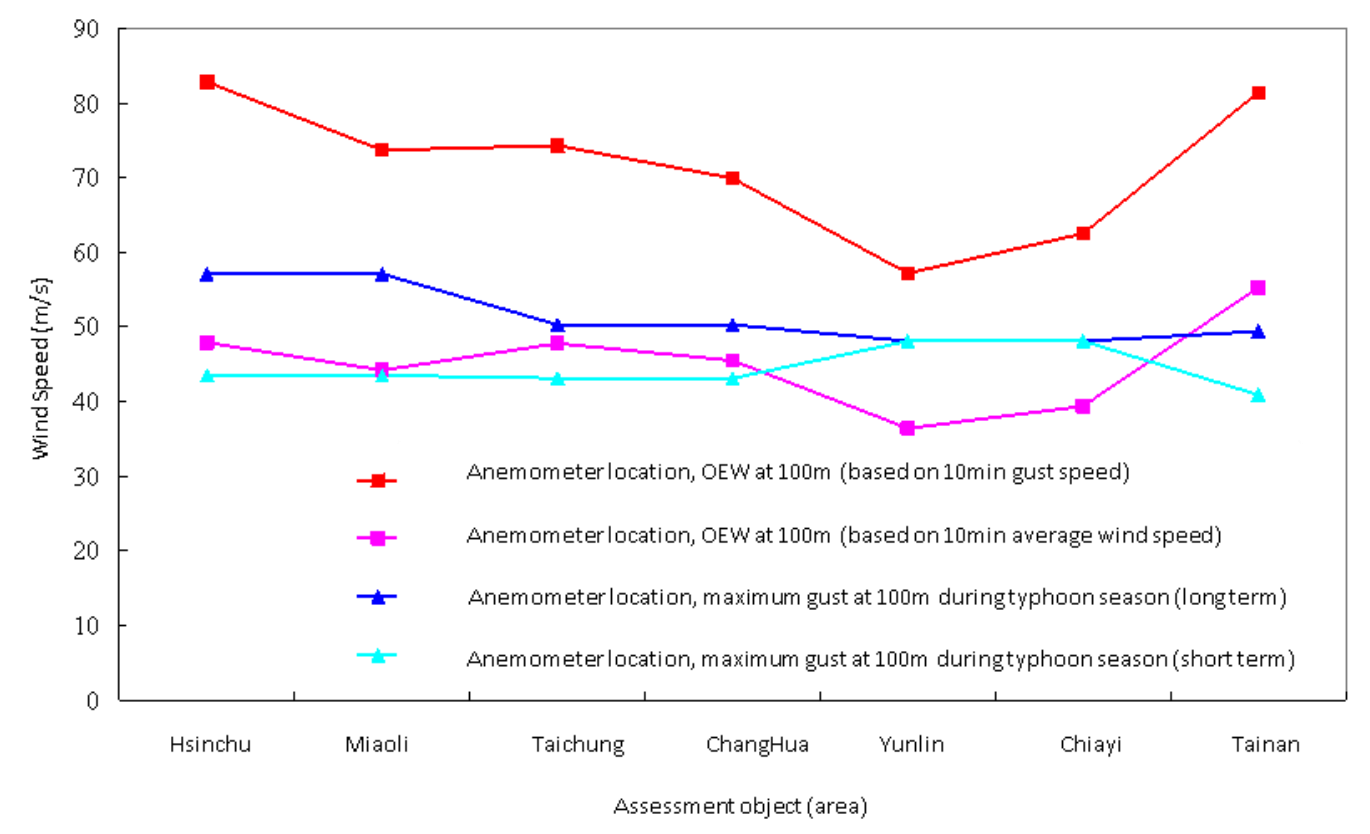

Figure 10. Estimated extreme wind speed and maximum gust wind speed during typhoon season. 
Table 4. OEW (Observed Extreme Wind) values (m/s) at a height of $100 \mathrm{~m}$.

\begin{tabular}{|c|c|c|c|c|c|c|c|}
\hline OEW $(\mathrm{m} / \mathrm{s})$ & (a) Hsinchu & (b) Miaoli & (c) Taichung & (d) Chang Hua & (e) Yunlin & (f) Chiayi & (g) Tainan \\
\hline Long term ${ }^{1}$ & $\begin{array}{c}47.9 \\
(1997.5-2012.8)^{3} \\
\end{array}$ & $\begin{array}{c}44.2 \\
(1997.5-2012.8) \\
\end{array}$ & $\begin{array}{c}47.8 \\
(2000.5-2011.12) \\
\end{array}$ & $\begin{array}{c}45.5 \\
(2000.5-2011.12) \\
\end{array}$ & $\begin{array}{c}36.4 \\
(2000.1-2011.12) \\
\end{array}$ & $\begin{array}{c}39.4 \\
(2000.1-2011.12) \\
\end{array}$ & $\begin{array}{c}55.3 \\
(2006.5-2012.6) \\
\end{array}$ \\
\hline Long term ${ }^{2}$ & $\begin{array}{c}82.8 \\
(1997.5-2012.8) \\
\end{array}$ & $\begin{array}{c}73.7 \\
(1997.5-2012.8) \\
\end{array}$ & $\begin{array}{c}74.3 \\
(2000.5-2012.8) \\
\end{array}$ & $\begin{array}{c}69.9 \\
(2000.5-2012.8) \\
\end{array}$ & $\begin{array}{c}57.2 \\
(2005.10-2011.12) \\
\end{array}$ & $\begin{array}{c}62.5 \\
(2005.10-2011.12) \\
\end{array}$ & $\begin{array}{c}81.4 \\
(2006.5-2012.6) \\
\end{array}$ \\
\hline Short term ${ }^{1}$ & $\begin{array}{c}43.0 \\
(2009.1-2011.12) \\
\end{array}$ & $\begin{array}{c}37.6 \\
(2009.1-2011.12) \\
\end{array}$ & $\begin{array}{c}43.0 \\
(2009.1-2011.12) \\
\end{array}$ & $\begin{array}{c}41.3 \\
(2009.1-2011.12) \\
\end{array}$ & $\begin{array}{c}36.1 \\
(2009.1-2011.12) \\
\end{array}$ & $\begin{array}{c}38.2 \\
(2009.1-2011.12) \\
\end{array}$ & $\begin{array}{c}36.3 \\
(2006.5-2008.12) \\
\end{array}$ \\
\hline Short term $^{2}$ & $\begin{array}{c}57.3 \\
(2009.1-2011.12) \\
\end{array}$ & $\begin{array}{c}51.5 \\
(2009.1-2011.12) \\
\end{array}$ & $\begin{array}{c}62.6 \\
(2009.1-2011.12) \\
\end{array}$ & $\begin{array}{c}58.5 \\
(2009.1-2011.12) \\
\end{array}$ & $\begin{array}{c}56.2 \\
(2009.1-2011.12) \\
\end{array}$ & $\begin{array}{c}59.1 \\
(2009.1-2011.12) \\
\end{array}$ & $\begin{array}{c}50.6 \\
(2006.5-2008.12) \\
\end{array}$ \\
\hline
\end{tabular}

${ }^{1}$ Based on 10-min average wind speed; ${ }^{2}$ Based on 10-min gust wind speed data; ${ }^{3}$ Wind speed data measurement period. 
The wind climate in the west Taiwan coastal area is the most severe during typhoon season, and it significantly affects the structural safety of marine facilities. This is also the period when offshore wind turbines are subjected to "extreme" wind speed. Therefore, we collated the aforementioned long-term and short-term maximum gust data within typhoon storms in the west coastal area and compared those with the data in Table 4. The results are shown in Figure 10. The extreme wind speed calculated from long-term 10 min maximum instantaneous gust speed is well above the extreme wind speed calculated from the long-term 10 min average wind speed, maximum gust (long-term) during typhoon season, and maximum gust (short-term) during typhoon season. The extreme wind speed calculated from long-term 10 min average wind speed is close to the maximum gust wind speed during the typhoon season. Therefore, such extreme wind speed can be safely used in subsequent structural designs.

\section{Conclusions}

This study first imported wind speed data measured by a tidal station (in Miaoli, Taiwan) and a buoy (in Tainan, Taiwan) into the WAsP simulation software to estimate the high altitude wind speeds for the two areas. Then, a Lidar system was set up near the tidal stations and buoys, and high-altitude wind speeds measured by the Lidar system were compared with the WAsP-estimated high altitude wind speed. The two data sources were found to be rather consistent, and regression analysis $\mathrm{R}$-squared values are in the range of 0.8-1. Long-term wind speed data observed by buoys and tidal stations in other areas were also imported into WAsP to create a forecast of wind speed at 50-200 m on the west cost of Taiwan (Hsinchu, Miaoli, Taichung, ChangHua, Yunlin, Chiayi and Tainan). At the same time, WAsP Engineering 3.0 was used to analyze extreme wind speed.

The results show that on the west coast of Taiwan, wind speed at $100 \mathrm{~m}$ is in the range of $9.32-11.24 \mathrm{~m} / \mathrm{s}$, and wind power density is approximately $1079-2665 \mathrm{~W} / \mathrm{m}^{2}$. Both values are far above those in the neighboring coastal area, which means that wind energy resources in the Taiwan coastal area are rich but undeveloped. According to extreme wind speed estimation results, when we use the long-term maximum 10 min instantaneous gust speed as a basis, the calculated extreme wind speed is well above the extreme wind speed calculated from other data sources. The extreme wind speed calculated from long-term $10 \mathrm{~min}$ average wind speed is close to the maximum gust wind speed during typhoon season; therefore, such extreme wind speeds can be used as reliable data for subsequent structural design. When long-term $10 \mathrm{~min}$ average wind speed is used as the calculation basis, the extreme wind speed in the west coast of Taiwan is in the range of $36.4-55.3 \mathrm{~m} / \mathrm{s}$.

\section{Acknowledgments}

The authors gratefully acknowledge the support provided by the Ministry of Science and Technology, Taiwan, ROC through Grant No. MOST 103-2218-E-006-011. Our sincere gratitude also goes to University Distinguished Professor Ta-Hui Lin at the Department of Mechanical Engineering, National Cheng-Kung University, Taiwan, for his facility support throughout the Lidar measurements. 


\section{Author Contributions}

Pei-Chi Chang and Chi-Ming Lai conceived and designed the experiments; Pei-Chi Chang and Ray-Yeng Yang performed the experiments; Pei-Chi Chang, Ray-Yeng Yang and Chi-Ming Lai analyzed the data; and Pei-Chi Chang wrote the paper.

\section{Conflicts of Interest}

The authors declare no conflict of interest.

\section{References}

1. Wind Turbines-Part 12-1: Power Performance Measurements of Electricity Producing Wind Turbines, 1st ed.; IEC 61400-12-1; International Electrotechnical Commission: Geneva, Switzerland, 2005.

2. Lima, L.A.; Filho, C.R.B. Wind resource evaluation in São João do Cariri (SJC)—Paraiba, Brazil. Renew. Sustain. Energy Rev. 2012, 16, 474-480.

3. Onat, N.; Ersoz, S. Analysis of wind climate and wind energy potential of regions in Turkey. Energy 2011, 36, 148-156.

4. Palaiologou, P.; Kalabokidis, K.; Haralambopoulos, D.; Feidas, H.; Polatidis, H. Wind characteristics and mapping for power production in the Island of Lesvos, Greece. Comput. Geosci. 2011, 37, 962-972.

5. Djamai, M.; Merzouk, N.K. Wind farm feasibility study and site selection in Adrar, Algeria. Energy Procedia 2011, 6, 136-142.

6. Sanz Rodrigo, J.; Borbón Guillén, F.; Gómez Arranz, P.; Courtney, M.S.; Wagner, R.; Dupont, E. Multi-site testing and evaluation of remote sensing instruments for wind energy applications. Renew. Energy 2013, 53, 200-210.

7. Wood, C.R.; Pauscher, L.; Ward, H.C.; Kotthaus, S.; Barlow, J.F.; Gouvea, M.; Lane, S.E.; Grimmond, C.S.B. Wind observations above an urban river using a new Lidar technique, scintillometry and anemometry. Sci. Total Environ. 2013, 442, 527-533.

8. Coutu, S.; Wyrsch, V.; Rossi, L.; Emery, P.; Golay, F.; Carneiro, C. Modelling wind-driven rain on buildings in urbanized area using 3-D GIS and Lidar datasets. Build. Environ. 2013, 59, 528-535.

9. Standridge, C.R.; Zeitler, D.; Nordman, E.; Boezaart, T.A.; Edmonson, J.; Nieves, Y.; Turnage, T.J.; Phillips, R.; Howe, G.; Meadows, G.; et al. Laser Wind Sensor Performance Validation with an Existing Gage; Grand Valley State University, Offshore Wind Project: Allendale, MI, USA, 2013.

10. Pichugina, Y.L.; Banta, R.M.; Brewer, W.A.; Sandberg, S.P.; Hardesty, R.M. Doppler Lidar-based wind-profile measurement system for offshore wind-energy and other marine boundary layer applications. J. Appl. Meteorol. Climatol. 2012, 51, 327-329.

11. Gumbel, E.J. Statistics of Extremes; Columbia University Press: New York, NY, USA, 1958.

12. An, Y.; Pandey, M.D. A comparison of methods of extreme wind speed estimation. J. Wind Eng. Ind. Aerodyn. 2005, 93, 535-545. 
13. Harris, R.I. Improvements to the method of independent storms. J. Wind Eng. Ind. Aerodyn. 1999, 80, 1-30.

14. Lee, B.H.; Ahn, D.J.; Kim, H.G.; Ha, Y.C. An estimation of the extreme wind speed using the Korea wind map. Renew. Energy 2012, 42, 4-10.

15. WAsP/WAsP Engineering. Available online: http://www.wasp.dk/ (accessed on 25 January 2015).

16. Jiang, D.; Zhuang, D.; Huang, Y.; Wang, J.; Fu, J. Evaluating the spatio-temporal variation of China's offshore wind resources based on remotely sensed wind farm data. Renew. Sustain. Energy Rev. 2013, 24, 142-148.

17. Wong, M.S.; Kwan, W.K. Wind Statistics in Hong Kong in Relation to Wind Power; Hong Kong Observatory: Hong Kong, China, 2002.

18. Yim, S.H.L.; Fung, J.C.H.; Lau, A.K.H. Mesoscale simulation of year-to-year variation of wind power potential over southern China. Energies 2009, 2, 340-361.

(C) 2015 by the authors; licensee MDPI, Basel, Switzerland. This article is an open access article distributed under the terms and conditions of the Creative Commons Attribution license (http://creativecommons.org/licenses/by/4.0/). 